\title{
O vocabulário do garimpo artesanal de diamantes: das funções da escala ao bater da peneira
}

\author{
The vocabulary of artisanal mining of diamonds: the scale \\ functions to hit the sieve
}

\author{
Maria Helena DE PAULA \\ Universidade Federal de Goiás/Regional Catalão (UFG/RC) \\ Gabriela Guimarães JERONIMO \\ Universidade Federal de Goiás/Regional Catalão (UFG/RC)
}

\begin{abstract}
RESUMO: Este estudo pretende analisar, por um viés terminológico, o vocabulário do garimpo artesanal de diamantes. Os termos selecionados para este trabalho são um recorte do corpus da pesquisa As grimpas lexicais e seus diamantes linguísticos: o vocabulário do garimpo artesanal de diamantes no município de Três Ranchos-Goiás (1944-1981), realizada por Jeronimo (2013). Respaldamo-nos, aqui, nos princípios da Teoria Comunicativa da Terminologia (TCT), proposta por Cabré (1999) ao trazer um novo olhar sobre a unidade terminológica, quando um item léxico nomeia um elemento da ciência ou da técnica. Sob este viés, apresentaremos como a técnica antiga cujas atividades iniciaram-se no Brasil colônia, com as primeiras extrações de ouro no litoral e, posteriormente, na região central do país, é nomeada pelo vocabulário do garimpo, nas memórias dos nomes das "coisas" do trabalho dos senhores que garimparam diamantes no município de Três Ranchos, sudeste goiano, até o ano de 1981.
\end{abstract}

PALAVRAS-CHAVE: Terminologia. Garimpo artesanal. Motivação linguística.

ABSTRACT: In a terminological perspective, this paper aims to analyze the vocabulary of artisanal mining of diamonds. The selected terms for this paper are part of corpus of the study "As grimpas lexicais e seus diamantes linguísticos: o vocabulário do garimpo artesanal de diamantes no município de Três Ranchos-Goiás (1944-1981)", made by Jeronimo (2014). We support, in this study, in the principles of the Theory of the Communicative Terminology (TCT), of Cabré (1999), in that she presents new vision about the terminological unit, designed as a lexical item in speciality, acquiring, thus, specific caracter when it denominates an scientific and/or technical element. In this conception we'll present how the old technique whose activities were initiated in colonial Brazil, with the first extraction of gold on the coast and subsequently in the central region of the country, is nominated by the vocabulary of mining, in the memories of names of the "things of the work" of men who panned diamonds in Três Ranchos, Goiás Southeast until the year 1981.

Key words: Terminology. Artisanal mining. Linguistic motivation.

\section{Introdução}

A atividade de extração de minérios e pedras preciosas é antiga, iniciando-se no Brasil já nos séculos XVII e XVIII, quando foram criadas pela Coroa portuguesa várias 
formas de fiscalização ${ }^{1}$ para controlar o desvio e o contrabando das riquezas retiradas das terras brasileiras. Além de impostos, os esforços dos colonizadores não bastaram para impedir que, através de um ato subversivo por parte daqueles que tiveram coragem de se arriscar e se embrenhar pelo proibido, surgisse a mais nova velha função: garimpeiro, de onde consequentemente derivaria o nome da prática, garimpagem, e do seu local de trabalho, o garimpo. Vale lembrar que com a escravização havia muitos africanos e afrodescendentes trabalhando nas minas e, posteriormente, nos garimpos também, principalmente os escravos fugidos.

Estes homens se escondiam nas grimpas $^{2}$ (ponto mais alto de uma colina, montanha ou qualquer tipo de edificação) com o intuito de garimparem fora dos domínios do físco, mesmo conscientes das rigorosas punições. Nas regiões de extração, existiam lugares de difícil acesso "[...] E foi nesses pontos excusos que surgiram os primeiros garimpeiros" (MACHADO FILHO, 1964, p. 12), uma vez que nestes locais a fiscalização demorava a chegar.

Assim, de um lado havia o minerador, aquele trabalhador autorizado pela Coroa a minerar, do outro, o garimpeiro, inicialmente, chamado de grimpeiro (por ficar escondido e isolado nas grimpas), um “[...] trabalhador autônomo, que não concordava com as condições impostas para a sua atividade, e se arriscava na vida fora-da-lei [...]" (SOUSA, 2012, p. 148).

Ainda sobre o termo garimpeiro, a hipótese de que com o passar do tempo, por meio da epêntese da vogal "a", provavelmente uma mudança fonética advinda da oralidade, pode ser comprovada através de registros ${ }^{3}$ escritos em que foi utilizada a sequência fonética anterior às modificações, como também por meio da referência etimológica disponibilizada no Dicionário Eletrônico Houaiss da Língua Portuguesa ${ }^{4}$ (2009), informações que coincidem com os acontecimentos históricos relatados pelos estudiosos que abordam a temática do garimpo.

Percebemos, então, que inicialmente, este trabalhador sobrevivia nas margens da ilegalidade ou, nas palavras de Gonçalves (2012), “[...] fugindo, aventurando, procurando e sendo procurado, grimpando nas serrarias, sempre escorregadio, atento e audaz [...] personagem odiado e perseguido rigorosamente [...]" (GONÇALVES, 2012, p. 117); e foi desta sucessão de acontecimentos que croaram das grimpas os primeiros garimpeiros na história do Brasil.

Notamos, assim, que esta afirmação de Gonçalves (2012) vai ao encontro do que Silva (2006) propõe em sua dissertação sobre os garimpeiros de esmeralda em Campos Verdes-Goiás, em que a prática destes trabalhadores (a garimpagem) era subversiva, constituindo uma identidade cunhada na ilegalidade e, naquele momento sócio-histórico e

\footnotetext{
1 Códigos Mineiros de 1603 (o quinto); Regimento dos Superintendentes, Guardas-mores e Oficiais Deputados para as Minas de Ouro (1720); Intendência das Minas. Ver mais detalhes em Silva (2006, p. 2633).

2 “[...] antepositivo, prov. do fr. grimper 'trepar, subir, elevar-se com o auxílio das mãos e dos pés, estenderse progressivamente para cima', f. nasalizada de gripper ver ${ }^{1}$ grip-; ocorre em vocábulos dos XIX em diante (salvo grimpa, doc. desde o Renascimento): [...] grimpador, grimpagem, grimpamento, grimpante, grimpar, grimpo [...]" (HOUAISS; VILLAR, 2009).

${ }_{3}^{3}$ Memória sobre as minas da capitania de Minas Geraes: suas descripções, ensaios, e domicilio próprio, de José Vieira Couto (1842).

4 “'...] antepositivo, do port. garimpeiro, f.epent. de grimpa + o suf. -eiro: 'o garimpeiro andava pelas grimpas em busca de ouro', observa J.P. Machado; ocorre em vocábulos de fins dos XIX em diante: garimpa, garimpado, garimpagem, garimpar, garimpeira, garimpense, garimpo [...]” (HOUAISS; VILLAR, 2009).
} 
cultural, estes homens eram considerados foras da lei, infratores que deveriam ser severamente punidos.

Neste ínterim, o garimpeiro se aliou ao quilombola, pois, de certa forma, ambos encontravam-se em condições semelhantes: o primeiro fugindo do fisco e o segundo do cativeiro, mas Machado Filho (1964) defende que mesmo se encontrando nesta situação de ilegalidade, o garimpeiro jamais deveria ser confundido com bandido ou comparado a ele, pois se tratavam, em sua maioria, de homens honestos, como corroboram os depoimentos/as entrevistas com os sujeitos da pesquisa, quando afirmam que havia "confiança cuns' os ôtro né, achava diamante do ôtro, amigo, entregava, diamante seu, achei ali e e[le]s tamém fazia o mesmo $\{\ldots\}$ é honesto, agora hoje num tem jeito de garimpá" $\left(\mathrm{G} 1 \mathrm{E} 1^{5}\right)$.

No entanto, sabemos que no acontecer dos anos, uma sociedade passa por modificações, em seu meio cultural, histórico ou político, de modo que outras ideologias são inculcadas, produzindo ou alterando alguns conceitos pré-estabelecidos. Isto não seria diferente com relação ao garimpeiro, visto que quando já não éramos mais colonos de Portugal, o garimpo e o contrabando, no sentido de garimpar às escondidas do fisco da Coroa, já não cabiam mais neste novo contexto. Porém,

[...] o nome de garimpeiro não foi substituído por outro e ficou designado o pequeno explorador das lavras, que, agindo em liberdade e dentro da lei, jamais perdeu suas características inconfundíveis, encarnando um dos tipos mais interessantes de nossa terra [...] (MACHADO FILHO, 1964, p. 16).

No encalço do que afirma este estudioso, percebemos ter havido uma pequena mudança no significado deste termo devido, especialmente, aos acontecimentos históricos da Proclamação da Independência do Brasil.

Desta feita, a identidade deste trabalhador, antes clandestino, mantém como uma de suas características o seu comportamento nômade, sempre se deslocando de um lugar para o outro, movido pela notícia de bamburro, isto é, novo achado da pedra preciosa pela qual "[...] indivíduos, que por sua conta e risco, enfrentavam os perigos dos sertões em busca de riqueza e sustento próprio [...]" (COSTA, 2007, p. 251). Neste afã de buscar a sorte ou de bamburrar, garimpeiros se tornam "[...] pessoas que abandonam famílias e se deslocam para onde foi descoberto um novo garimpo. Lá trabalham, se ganharem dinheiro, logo buscam a família [...]"' (SILVA, 2006, p. 29).

A família não ficava desamparada porque, na maioria das vezes, o garimpeiro trabalhava para o fornecedor, que mantinha o garimpo fornecendo os mantimentos e tudo que fosse necessário para a sobrevivência dos trabalhadores e de sua família (no caso dos que eram casados), como também para a extração dos diamantes, como bem explica um dos entrevistados:

\footnotetext{
${ }^{5}$ Este é um código que utilizamos para identificar a pessoa entrevistada, pois não fomos autorizados pelo Comitê de Ética em Pesquisa a divulgar o nome do (a) entrevistado (a). Neste caso, trata-se de um trecho da primeira entrevista realizada com o primeiro garimpeiro, por isto G1E1.
} 
[...] Ele tinha tazido o fornecimento... pá dexa o fornecimento [...] Arroiz, feijão, açucar, café esses trein né... e carne. Tud'é trazido. Vem muito trein. Aí ele falô: Ó tem esse trein aí, cê divide aí cuns casado [...] Aí chamei ês 1[á] em casa e nóis dividiu o trein. Ai falei pá (...): (...) qu'é que cê acha? Eu vô garimpá mais ou... ixprementá mais no garimpo ou... Ela falô: Ah! Esses trem que tem aí dá pá eu e os minino cumê muitos dia, pode i[r] [...]" (G2E1).

Atualmente, com o discurso que circula sobre a preservação ambiental, a identidade do garimpeiro passou por mais uma modificação, o de poluidor e destruidor do meio ambiente, "[...] agentes de poluição mercurial, destruidores de sociedades indígenas e várias outras formas de enfrentamento" (SILVA, 2006, p. 33).

Além destas modificações que ocorreram em torno desta profissão de uma forma geral, cabe falarmos sobre as mudanças locais e, por isto, mais restritas. A atividade garimpeira no município de Três Ranchos-Goiás, por questões políticas, históricas e socioculturais, passou por deslocamentos específicos devido ao represamento do Rio Paranaíba para a construção da UHE de Emborcação, que culminou no alagamento dos garimpos, impossibilitando a atividade, resultando em um "[...] deslocamento involuntário dos garimpeiros" (SOUSA, 2012, p. 23). Porém, inusitadamente, a maioria, ao invés de fazer o costume de procurar por outros garimpos, permaneceu na cidade assumindo outras profissões, pois:

[...] por conta do alagamento dos sítios onde garimpava, o garimpeiro tornou-se um excluído típico. Em virtude da nova configuração econômica estabelecida, essencialmente voltada para a prestação de serviços relacionados ao turismo, muitos dos antigos garimpeiros de Três Ranchos se dispõem a trabalhar como serventes, cozinheiros, caseiros, jardineiros, vigilantes etc., provocando-lhes um tipo de banimento [...] (SOUSA, 2012, p. 130).

Percebemos que estes homens que garimparam em Três Ranchos fogem um pouco à regra em um aspecto muito específico, o fato de terem se "apegado" à cidade e ali criado raízes, quando o mais esperado e comum seria que, em virtude do alagamento, eles seguissem sua sina, à procura de outros locais para garimpar. No entanto, mesmo com um grande pesar, se fixaram ali trabalhando em outras profissões, submergindo junto com os garimpos os seus sonhos diamantinos e "[...] sua esperança, a esperança teimosa e quase infantil, que diante de nada esmorece [...]" (MACHADO FILHO, 1964, p. 29), como reiteradamente deixam notar em suas falas.

Entendemos, assim, que a prática da garimpagem em Três Ranchos faz parte da história deste lugar sendo, por muito tempo, uma das formas de subsistência das pessoas que ali habitavam e, talvez, uma das mais importantes. De acordo com a história oral contada por seus moradores, esta prática tem uma importância cultural inquestionável para a formação econômica, social e histórica da cidade.

Este breve percurso histórico teve o intuito de apresentar o garimpo artesanal como uma técnica antiga e, embora o vocabulário utilizado pelos que compartilhavam desta prática não venha de um embasamento científico (como, posteriormente, encontraríamos na área da mineralogia) o que verificamos é a existência um vocabulário terminológico ${ }^{6}$, como verificaremos na seção destinada às análises.

\footnotetext{
${ }^{6}$ Compartilhamos este termo de Murakawa (2013, p. 89-90), por entendermos que esta concepção também se aplica ao corpus que será analisado neste trabalho.
} 


\section{Do corpus de análise}

Os termos que analisaremos foram selecionados a partir de um corpus de pesquisa mais amplo, que foi material de estudo da dissertação de mestrado As grimpas lexicais $e$ seus diamantes linguísticos: o vocabulário do garimpo artesanal de diamantes no município de Três Ranchos-Goiás (1944-1981), de Jerônimo (2014).

O corpus desta pesquisa se constituiu a partir de fonte oral por meio da realização de entrevistas que foram, posteriormente, transcritas. As entrevistas foram feitas com homens que trabalharam no garimpo de diamantes em Três Ranchos e com pessoas que com eles conviveram.

Para a composição do material da pesquisa, foram entrevistadas treze pessoas, sendo dez ex-garimpeiros, uma esposa de garimpeiro, um fornecedor e um morador que conviveu diretamente com garimpeiros, todos numa faixa de sessenta a oitenta anos de idade, exceto este último, com 48 anos.

Além de se tratarem de dados que foram coletados a partir da oralidade, vale ressaltar que muitos destes termos já não são mais utilizados devido à extinção desta atividade, seja porque surgiram novas tecnologias, seja por conta do discurso recorrente sobre a preservação da natureza que nada tem impedido a exploração em massa por parte das mineradoras de grande porte.

O garimpo que estamos chamando de artesanal era uma atividade realizada manualmente e que necessitava de, no mínimo, dez homens a depender da profundidade do local escolhido para trabalhar e da força das águas. No caso de Três Ranchos, o interesse dos garimpeiros era o diamante, pois, segundo eles, ali encontrava-se desta pedra preciosa em abundância.

Ainda sobre os dados, foram selecionadas cento e dezoito lexias das quais vinte e oito são topônimos. Usamos o termo lexia, neste primeiro momento, pois a pesquisa de maior fôlego foi realizada sob um viés lexicológico, em que trabalhamos com o princípio da motivação já discutido por Platão, em Crátilo e, também, o conceito dos campos lexicais proposto por Coseriu (1977) e Geckeler (1976). No entanto, ao entendermos o garimpo como uma técnica e nos determos neste mesmo corpus pela perspectiva da Terminologia do século XX, considerando também as questões históricas que perpassam esta atividade, uma análise de cunho terminológico se nos mostrou possível e enriquecedora.

Como mencionamos, os itens léxicos foram estruturados em campos lexicais, em que do campo principal Garimpo artesanal de diamantes (arquilexema), se ramificam cinco macrocampos. Destes cinco, alguns também possuem ramificações, os microcampos, em que do macrocampo Funções da escala, temos o microcampo $O$ correr da escala; em Lance de cabo/bater cabo/mergulho de exploração, os microcampos Trechos de garimpo e Formas de diamante; em Extração do cascalho, os microcampos Tipos de garimpo e Sinalizações; e, no último macrocampo Venda das pedras, ramificam-se os microcampos Unidades de medida e Tipos de diamante. Assim, estruturamos todos os itens lexicais que constituem o corpus de pesquisa. No entanto, no estudo ora apresentado analisaremos apenas dois: Funções da escala e Lavagem do cascalho. 


\section{Das funções da escala ao bater da peneira}

Como discutimos anteriormente, o garimpo é uma técnica que surgiu nas margens da ilegalidade por uma necessidade social de muitos mineradores que eram explorados pela Coroa. Praticamente tudo que era extraído das terras brasileiras deveria ser rigorosamente destinado aos colonizadores portugueses. No entanto, alguns destes trabalhadores, muitos deles escravos, se encorajaram e subverteram as leis do fisco.

Desta forma, por razões socioeconômicas e culturais, este movimento passou a criar suas raízes, fazendo emergir dos lugares mais escondidos a técnica da garimpagem e, com ela, novos termos que serviram para nomear tudo que estivesse a ela circunscrito, desde o nome da função que cada garimpeiro exercia até a venda das pedras.

Assim, por mais que esta prática, em sua forma artesanal, tenha se extinguido, especialmente no município de Três Ranchos, devido ao represamento do rio Paranaíba, os termos, outrora utilizados, se encontram preservados na memória daqueles que compartilharam a lida no garimpo, especificamente, o de escafandro ${ }^{7}$.

Deste modo, concordamos com o que diz Barros (2004):o que faz uma unidade lexical um termo é o contexto em que está sendo usada, isto é, as condições pragmáticas em que ela é empregada. Muitas vezes, os especialistas se servem de itens lexicais em uso na língua geral para nomearem as novas "coisas" que foram criadas, seja no âmbito de uma área científica ou de uma técnica, pois "[...] é no contexto e no discurso que o termo é investido de valor. Não visa assim, a monossemia absoluta do termo, contrariamente à posição de Wüster" (BARROS, 2004, p. 50).

Esta concepção, no campo da Terminologia, foi difundida, principalmente, após o advento da TCT, proposta por Maria Teresa Cabré. A estudiosa reconhece a importância da teoria proposta por Wüster, mas considera que alguns princípios precisavam ser revistos, de modo que o olhar sobre a unidade terminológica tornou-se mais amplo e menos restrito, em que não seria mais o caso de considerar as terminologias como subsistemas independentes da língua em uso, mas de campos específicos que necessitam de uma nomeação também específica. Reconhecemos, assim, que estamos lidando com uma área que dialoga com as outras, isto é, transdisciplinar.

Por este prisma, analisaremos os termos selecionados com base nos princípios da TCT. Iniciaremos pelas Funções da escala, campo de termos no qual compreendemos a organização dos garimpeiros no leito do rio e a função que cada um exercia na balsa.

$\mathrm{Na}$ maioria das vezes, o fornecedor, dono das máquinas, procurava por um garimpeiro de sua confiança para gerenciar a balsa; geralmente, o gerente era o mergulhador mais experiente, que seria responsável pela escolha do restante da turma e pela verificação quanto à segurança do lugar escolhido para a extração das pedras, sendo este o primeiro a mergulhar.

Quando o mergulhador que estava no fundo considerava o seu trabalho por encerrado, retornando à superfície, o próximo a descer era o manguereiro, o responsável pela vigilância da mangueira por onde o ar fornecido pelas bombas devia chegar até o garimpeiro que estava trabalhando.

O garimpeiro que estava na função da separação do cascalho "bom" das pedras inúteis era o canoeiro que, em sequência, assumiria o ofício de manguereiro. Junto com ele ficava o corre-dinheiro, cujo papel era receber os sinais daquele que estava garimpando e puxar para a balsa os sacos cheios de cascalho. Depois que o cascalho diamantífero era

\footnotetext{
${ }^{7}$ Também conhecido como garimpo de leito ou mergulho a saco, acontece no leito do rio, porém em lugares mais profundos, em que o garimpeiro utiliza um equipamento de mergulho para sobreviver no fundo por muitas horas.
} 
separado do que não o era, este inutilizável era colocado numa canoa subserviente, onde se encontrava o parasita, encarregado de jogá-lo fora, preferencialmente, num lugar mais distante para não "sujar o serviço".

Chegando às últimas funções da escala, tínhamos o vice-parasita que, além de auxiliar o parasita, ficava à disposição dos bombeiros para revezar nos lugares muito fundos em que eram necessários mais homens para tocar a bomba que forneceria o ar ao mergulhador da vez.

Esta movimentação da escala com as trocas de funções acontecia toda vez que o mergulhador que estava retirando o cascalho voltava para a superfície, o que os nossos entrevistados nomeiam de correr a escala. Segundo eles, nem sempre a escala corria nesta ordem por conta de imprevistos que aconteciam, como o caso de algum garimpeiro que jogava o capacete, propondo a algum companheiro de balsa que mergulhasse no seu lugar, para depois, dividirem os lucros, no chamado mergulho a vinte e cinco ou descer a vinte cinco. Alguns contam também que havia ocasiões em que a pessoa descia, mas não conseguia "mandar nada", o que eles chamam de suicidar o mergulho.

Além disto, tinha também a troca de escala, um acordo entre os garimpeiros de trocarem de função dentro de uma determinada escala.

Como nos disse um dos garimpeiros "apesar de se[r] um serviço rústico, até funcionava direitinho" (G3E1), em que pudemos perceber que se tratava de uma atividade embebida por companheirismo, confiança e sonhos.

Assim, obedecendo à ordem da escala, da função mais baixa para a mais alta, temos os termos: bombeiro; vice-parasita; parasita; corre-dinheiro; canoeiro; manguereiro. Como ações neste cenário da escola, temos: correr escala; mergulhar a vinte e cinco/ descer a vinte e cinco; troca de escala; jogar o capacete; suicidar o mergulho. Podemos perceber que todos são formados a partir de unidades léxicas existentes na língua em uso, mas que, neste contexto, adquirem significado específico. Outra característica também notável e recorrente nas outras terminologias é o princípio da motivação, discutido por Krieger (2013):

[...] a opacidade de denominação, típica do léxico comum, não tem correspondência direta e absoluta no campo do léxico especializado. Neste, a tendência a um processo denominativo motivado traduz uma tentativa consciente de que a denominação seja capaz de refletir o conceito [...] (KRIEGER, 2013, p. 32).

Assim, a partir da descrição detalhada de cada uma destas unidades terminológicas, percebemos melhor a questão da motivação e, ainda, da formação morfossintática de cada uma delas.

Bombeiro é o substantivo que nomeia a função mais baixa dentro da escala, porém de suma importância, "cê cumeçava na bomba, bateno bomba, aí discia um lá no fundo cê tava bateno bomba, ês era dois, trêis bombero... né, que batia $\{\ldots\}$ é er'os bombero" (G6E1). Trata-se de um processo de derivação por sufixação, em que temos a palavra base bomba (nome da ferramenta que fornecia o oxigênio ao mergulhador) acrescida do sufixo - eiro (formador de substantivos), sendo que a sua motivação estaria na palavra base, em que a morfossintaxe da língua é respeitada, segundo a mesma lógica das palavras fazendeiro, leiteiro e porteiro.

Vice-parasita, dentro da escala, era uma função intermediária de quem, além de ajudar na bomba, quando necessário, deveria prestar auxílio ao parasita: "Ele batia bomba, juntos c'os bombero, mais hora que fosse discarregá a canoa, ele ia junto com o parasita, era os dois" (G10E1). Sendo assim, na próxima escala a ser tirada, o vice-parasita passaria 
para a função de parasita, o que justifica o item vice na criação desta unidade terminológica.

Parasita é o nome de uma das funções da escala em que temos uma motivação complexa, que pode ser explicada por analogia com o parasita enquanto "organismo que vive de e em outro organismo, dele obtendo alimento e não raro causando-lhe dano" (HOUAISS; VILLAR, 2009), porque, ao lado da balsa, ficava uma canoa subserviente para o depósito das pedras desnecessárias o que, de certa forma, lembra o comportamento de um parasita. Desta forma, o garimpeiro que estava naquela função recebia o nome de parasita numa relação metonímica, como podemos confirmar na citação que segue:

pur exemplo a canoa né $\{\ldots\}$ canoa tá tudo trabaiano, intão fica uma patráis lá assim sobservênça né, tirava [...] só purque chamava parasita... a canoa... nóis punha o nome nela de parasita purque ficava [...] pa lá né, ficava queta, onde tirava... suponhamo, saíu uma canoa cheia de pedra né, aí encostava aquela $\{\ldots\}$ esperan'aquela inchê pá podê $[\mathrm{en}] \operatorname{co}[\mathrm{s}] \mathrm{ta}$ ela $\{\ldots\}$ (G4E1).

O termo parasita é utilizado também tanto na terminologia da medicina quanto na da biologia. Neste caso, teríamos um caso que Krieger (2004) chama de polivalência, uma vez que é um termo utilizado em terminologias distintas, que adquiriu, porém, significados diferentes em cada uma delas.

Corre-dinheiro é o nome de mais uma das funções da escala, "corre-dinhero $\{\ldots\}$ é purque ele ficava só no mei'do sarilho pá atendê o sinal do mergulhadô \{...\}" (G2E1)". A motivação deste termo é mais complexa, está relacionada ao movimento de puxar o saco de cascalho para superfície através de um sarilho que corre e ao cascalho que estava depositado dentro dele, em que havia a probabilidade de ter algum diamante (que dará dinheiro) - desta associação e criatividade lexical, temos corre-dinheiro.

Canoeiro nomeia a função dentro da escala daquele que "tá na canoa, ele fica por conta de surucá o cascái” e, por ele ficar dentro da canoa de cascalho, é assim nomeado. Podemos perceber que se trata de um signo semi-motivado, criado através do processo de derivação sufixal com o acréscimo do sufixo - eiro à palavra base canoa, assim como ocorre com bombeiro.

Manguereiro era uma das funções mais delicadas da escala, em que o garimpeiro

ficava sempre cum manguero ali na proa, que qualqué coisa ali [a]normal tinha que dá nutiça, se o cara rodasse ali pur exemplo uma água forte, no manguero ali cê sabia, que o manguero ia forçava sua mão, e se o cara viesse tamém imbora ele sabia que pel'as bôia que o capacete sortava ele sabia que o cara tava vin'imbora $\{\ldots\}$ e aí ele ajudava colhê o manguero pra cima" (G10E1).

Como pudemos conferir através da explicação do entrevistado, quem estava nesta função deveria ficar atento o tempo todo a qualquer movimento na mangueira por onde passava o oxigênio; assim, por ele ser o "vigia da mangueira", temos, pelo processo de derivação sufixal, manguereiro.

Correr a escala ocorre quando o mergulhador que está no fundo retorna para a superfície, movimento que acontece em cima da balsa, como bem explica um dos entrevistados: 
intão a escala curria assim: tinha o camarada que tava no fundo, manguerero, o... o canoero... o canoero vem depois né, o da canoa de pedra, depois vinha o corre-dinhero, depois o canoero, sabe? $\{\ldots\}$ É, curria assim, tudo bonitim, ali $\{\ldots\}$ ah... parasita é a canoa de pedra $\{\ldots\}$ é o canoa de pedra $\{\ldots\}$ é o parasita $\{\ldots\}$ é... vamo cumecá co'... co'... purque na... o aparelho pá funcioná bem, além do cuzinhero que tinha $\{\ldots\}$ tinha o cuzinhero também, nó[s] vamo falá sobre isso. Pra funcioná bem, pelo menos oito pessoa, cê já notô que nóis só falô o nome só de quato, o que tava no fundo... é... de cinco... o que tava no fundo, o manguera, corre-dinhero, parasita que é a canoa de pedra e o... e o... a $\{\ldots\}$ canoero 'xatamente. Cê notô que sobrô mais quato né... não, sobrô mais trêis, esse trêis sabe qual a escala dele? Era batê bomba. Que aquele que sai do fundo, vai lá... o canoero mais o mergulhadô, pega canoa vai pô um... o produto dele, do mergulho lá no barranco. Aí volta os dois. Aquele que saiu do fund'água, primera coisa dele, era batê bomba, mais entre os trêis bombero, tem dois na frente dele, intão aquil'ali, quando ele... ele... mergulhava os dois que tava na frente dele bateno bomba, aí ele já ia pra quê? Já ia pra... pro parasita, o canoa de pedra $\{\ldots\}$ é... a hora que chegô a veiz dele, dele saí da escala de bomba, primero ele ia pra parasita, canoa de pedra, depois ele ia pa cordinha, depois pa canoa de cascalho de novo e assim por diante, até corrê a roda (G3E1).

A utilização do verbo correr se relaciona com o movimento que os garimpeiros faziam, saindo de uma função para outra e escala porque eles trabalhavam escalados, em que cada um exercia uma atividade diferente.

Mergulhar a vinte e cinco ou descer a vinte e cinco era uma espécie de negociação entre dois mergulhadores, quando um deles jogava o capacete.

pur exemplo, às veiz tinha um, chega no lugá tinha medo de $\mathrm{i}[\mathrm{r}] \ldots$ ele ficava co'medo dava pra um que tinha corage a vinte cinco... aí é vinte cinco por cento, cê pegava um diamante vindia, vamos supô vende por cem mil, cinquenta é do fornecedô, vinte cinco do merguiadô e vinte cinco do ôto que deu o mergulho, ess'é o vinte cinco qu'ês falava (G6E1).

A partir desta explicação, pudemos compreender o que motivou a criação deste termo, que se associa à porcentagem de $25 \%$ que seria destinada a cada mergulhador neste tipo específico de divisão de lucros.

Troca de escala era a ocasião em que o mergulhador da vez desistia de descer e propunha a algum companheiro ir em seu lugar para, depois, dividirem o lucro, um caso de mergulho a vinte cinto:

ele pegava e me chamava, se eu acha interessante, saí da minha, ele ia pra minha escala, o que eu tava fazeno, se eu tivesse bateno bomba ele ia batê bomba no meu lugá, mergulhava no... chamava troca de escala né... aí ele mergulhava vinte cinco cumigo lá e eu ia fazê a escala dele, iss'aí era uma coisa eventual que acontecia, né, mais era comum $\{\ldots\}$ Aliáis, todo dia dava isso im cima da balsa (G3E1).

Temos, então, o verbo trocar, pois de fato havia uma troca de escala porque isto acontecia dentro da escala, com a alteração das funções. 
Jogar o capacete está relacionado à desistência do mergulho, quando o garimpeiro da vez desistia de descer "ês falava que jugav'o, jugava o capecete, falava assim: 'Cê jogô o pano" (G10E1). No que se refere à motivação, temos uma ligação com o equipamento, $\mathrm{o}$ capacete de bronze do escafandro, uma vez que o garimpeiro jogou o capacete, desistiu. Quando isto acontecia, o desistente vendia o seu mergulho a vinte e cinco, ou seja, aquele que mergulhasse dividiria pela metade os cinquenta por cento do lucro com o outro.

Suicidar o mergulho era uma expressão utilizada nas ocasiões em que:

a pessoa ia pa tirá o mergulho, às veiz tava muito cascái né, discia e por uma razão ou ôto ele num consegui mandá o cascái e se ele puxava o saco lá e mandasse um, que seja um litro de cascái e saisse im cima ele perdeu o mergui $\{\ldots\}$ suicidô" (G10E1).

Percebemos que o verbo suicidar é usado em forma de metáfora, no sentido de que o mergulho foi finalizado antes da hora. No que se refere à Lavagem do cascalho, este era o procedimento que, geralmente, se realizava aos sábados e, às vezes, aos domingos. Era neste momento que o trabalho da semana inteira ganhava significado.

O tratamento com o cascalho começa já na balsa em que ele é surucado pelo canoeiro com o auxílio do parasita, no intuito de separar o que é diamantino das pedras inúteis. A criação deste verbo foi motivada devido ao nome da peneira utilizada para a realização deste procedimento: a suruca, surucona ou surucão, peneira de malha mais grossa. Feito isto, o cascalho surucado (aquele que passou pela suruca) é levado para o paiol de cascalho do garimpeiro que o extraiu. Os paióis ficavam no leito do rio e cada mergulhador tinha o seu. Eram locais que eles limpavam e organizavam especificamente para depositar o cascalho.

Como foi dito, a lavagem era feita aos sábados e domingos. Desta forma, já nas margens do rio, cada qual com seu terno de peneiras, constituído pela suruquinha, grossa, média e fina, quatro peneiras colocadas uma sobre a outra, de acordo com a espessura da malha, da mais grossa para a mais fina, iniciavam-se as lavações, individualmente. Era um momento solitário, acompanhado pela expectativa a cada bater da peneira, o ato de chacoalhar o cascalho e virar a peneira, batendo-a no chão.

Com este movimento, o cascalho formava uma roda e, na maioria das vezes, o diamante já saía croado, visível por cima da forma; em outros, saía embuchado, isto é, por baixo da forma. Nestes casos, era necessário cortar a forma com o auxílio de uma pazinha para se certificar de que não havia mesmo diamante ali. Vale lembrar que se tinha forma em abundância, os garimpeiros costumavam dizer, ao virarem a peneira, que havia forma de arco a arco.

Muitas vezes, acontecia de o cascalho estar queimando, o que significava que ali a sorte não estava favorável, levando-os a correr o trecho. Outras vezes, bamburravam, pegando boas pedras, "tirando a sorte grande". A alegria era maior na ocasião em que o diamante croava de suruca ainda no leito do rio, quando o cascalho passava pela suruca, o que significava quebrar o pau, pois como esta é uma peneira de malha bem grossa, o diamante encontrado ali só poderia ser uma pedra de tamanho considerável. Os diamantes de menor extensão eram guardados no picuá, uma espécie de recipiente confeccionado com osso de animais ou bambu.

Entendido como ocorre esta etapa, seguimos para a descrição mais detalhada de cada unidade terminológica, para compreendermos um pouco mais como acontece o processo da nomeação na técnica da garimpagem artesanal. Novamente, não faremos em ordem alfabética, mas na ordem dos acontecimentos como nos foi narrado durante as entrevistas. 
Cada garimpeiro possuía o seu paiol de cascalho, local em que o cascalho extraído seria depositado até o dia da lavação, daí a motivação através da locução adjetiva de cascalho: "é paiol $\{\ldots\}$ é... cada um tinha o paiol de pô o cascái né... num punha junto não, só punha o cascái junto quand'era bozó $\{\ldots\}$ ” (G6E1). Segundo Krieger (2013), este tipo de estrutura (substantivo + preposição + substantivo) costuma ser bastante recorrente nas terminologias, algo que poderemos verificar, novamente, no próximo termo a ser analisado.

Terno de peneiras é "as trêis penera que usa $\{\ldots\}$ é que usa $\{\ldots\}$ só trêis, não, pode usá quato tamém, tem lugá que ês usa quato $\{. .$.$\} era a fina, a média, a grossa, a suruquinha$ e a suru'a sucucona tamém, tem a surucona" (G9E1). Ou seja, é o conjunto de peneiras, em que, segundo os garimpeiros, as três principais eram a grossa, a média e a fina, o que melhor justifica o uso do item terno "conjunto de três entidades, seres, objetos etc. de igual natureza; trilogia, trio, trindade" (HOUAISS; VILLAR, 2009); e a locução adjetiva de peneiras é motivada pelo objeto que compõe cada terno, neste caso, a peneira.

No que se refere aos tipos de peneira, os adjetivos que acompanham este substantivo são motivados pela espessura da malha deste instrumento de trabalho usado na etapa da lavação do cascalho, em que temos peneira fina, peneira grossa e peneira média: "É as trêis penera que usa $\{\ldots\}$ é que usa $\{\ldots\}$ só trêis, não, pode usá quato tamém, tem lugá que ês usa quato " $\{\ldots\}$ era a fina, a média, a grossa" (G6E1).

Surucar trata-se de um termo já registrado em acervo lexicográfico (HOUAISS; VILLAR, 2009), como o ato de "vir abaixo, desmoronar, ruir (esp. terra); afundar, desabar". Assim, temos duas hipóteses: a primeira é que este item lexical poderia ser utilizado no garimpo por uma extensão de sentido, o que não seria uma fuga ao sentido, uma vez que surucar o cascalho é quando o cascalho diamantino "vem abaixo", separandose das demais pedras. A segunda e a que adotamos a partir da análise do corpus se trata de outra palavra, uma derivação regressiva motivada pelo nome da peneira (suruca):

Porque a pinera, a pinera é grossa, essa, essa num vai pa lavá não, ess'é só lá im riba da canoa $\{\ldots\}$ grossa assim ó (gestos) passa as pedra desse taman[ho] só $\{\ldots\}$ suruca $\{\ldots\}$ é [e]la é larga... suruca, passa as pedra, pa num passá as pedrona grande, pa num estrová nóis lavá cascái, senão num junta forma (G8E1).

Suruquinha, diminutivo de suruca, porque "a malha dela é um poco menor $\{\ldots\}$ é... purque muitas veiz a suruquinha $\{\ldots\}$ ela, ela batia, ela também quando o cascalho tinha muita forma" (G3E1).

Cascalho surucado; cascalho despedrado ou cascalho desemburrado são três termos utilizados para nomear o mesmo referente, momento em que "ele já é penerado lá, tirado as pedra maior, nóis falamo surucado, né, o cascalho saía já no jeito de i[r] pá lavadera todo despedrado né, a canoa $\{\ldots\}$... (G3E1). Temos aqui um caso de sinonímia, que na TGT (Teoria Geral da Terminologia, proposta por Wüster) não seria um caso aceitável, mas que na TCT se trata de um fenômeno admissível, pois "[...] tal como as outras unidades lexicais dos sistemas linguísticos, as especializadas sofrem processos de sinonímia e comportam variações das mais diferentes naturezas" (KRIEGER; FINATTO, 2004, p. 79).

A motivação no caso do surucado vem do nome dado à peneira específica para este processo: a suruca. Porém, aqui não se trata de uma derivação sufixal a partir da palavra base suruca, em que haveria apenas o acréscimo do sufixo -ado, mas do verbo surucar no particípio. 
Sobre o adjetivo despedrado teríamos aqui uma espécie de antônimo de empedrado. Seguindo a lógica de formação de palavras da língua portuguesa falada no Brasil, acrescentaram o prefixo des- à palavra base, que é utilizado em sua maioria para indicar a falta de algo, como em desamor, desilusão. A motivação viria do processo de separação do cascalho diamantino das pedras, ou seja, despedrá-lo, tirar-lhes as pedras inúteis.

Quanto ao adjetivo desemburrado não encontramos nas acepções dicionarizadas nenhuma referência a esta etapa, mas percebemos uma pequena associação, mesmo extremamente tênue, com alguns dos significados apresentados para o verbo desemburrar já que o termo em análise não está registrado nos acervos que consultamos. No dicionário, o sentido está voltado para o ato de "[...] dar ou adquirir boas maneiras; educar(-se), polir(se), desembaraçar(-se) [...]" (HOUAISS; VILLAR, 2009). Existe a possibilidade de os garimpeiros terem relacionado este significado com o procedimento feito com o cascalho, em que o diamantino se desembaraçaria das pedras indesejadas. No entanto, trata-se apenas de uma hipótese para este sentido dado.

Diamante croado tem sua motivação relacionada ao verbo croar, assim, "Quando, quando a forma é mai[s] baxa cê bate, bate, o diamante saía por ribinha assim ó, croado $\{.$.$\} é pur ribinha, cê já catava ele \{. .\}$.$" (G8E1).$

Diamante embuchado, ao contrário do croado, era o caso do diamante que tinha saído debaixo na forma, isto é:

É quando cê vai lavá... cê lava o cascái aí cê vai batê a penera, cê lava, junta a forma, depois cê vai lá e bate $\{\ldots\}$ é bate a pinera $\{\ldots\}$ fica... fica a forma por cima certim, o diamante se tivé cê vê ele por cima da forma, argum sai imbuchado, que ês fala, imbuchado é quando ele num croa, quando ele num croa cê vai lá cê num vê ele e cê vai passá a pazinha, aí cê acha ele às veiz imbuchado $\{\ldots\}$ é nome imbuchado purque ele num croô (G6E1).

Apesar de a unidade terminológica embuchado estar dicionarizada, não há significado que se aproxime deste apresentado pelo entrevistado. Poderia ocorrer, neste caso, uma extensão de sentido por analogia, pois no acervo lexicográfico em que temos nos baseado, este item léxico é descrito como aquele ou aquela "[...] que não se manifesta por falta de conhecimento ou por não poder divulgar o que sente ou pensa [...]" (HOUAISS; VILLAR, 2009) e, no garimpo, como citado, é o diamante que não se "manifesta" por cima da forma.

Forma de arco a arco é uma expressão utilizada pelos garimpeiros para quando a forma estava abundante, deixando as peneiras cheias de um arco ao outro, como explica um dos senhores descontraidamente:

É... num sei, tem tanta coisa... uns falava que tava chorano, ôtos falava tá derreteno (risos) quan[do] tava, dava iss'aqui, dava muita forma... chegava falava 'É $o$ treim tá de arc'a arco', sabe? Que tava pegano chei'que tava dano os arco da pinera. 'Forma lá de arc'a arco' $\{\ldots\}$ intão quan[do] nóis era soltero e ia no baile que tava bom né, tinha muita moça 'Ih! Moça lá tá de arc'a arco' sabia que tava muita, né $\{\ldots\}$ muita moça (risos) (G5E1).

Quebrar o pau era uma expressão utilizada quando, ao surucar o cascalho, saísse alguma pedra de diamante, o que significava ser uma pedra de tamanho considerável "o cara tava lavano o cascái na balsa lá que pegava um diamante, aí ele gritava assim ó ' $O$ 
pau quebrô', e pegava, se era de trêis quilate, pegava trêis pedra e sabia até o taman[ho] do diamante (risos), tinha muito ditado garimpero, né" (G7E1). Não percebemos, neste caso, uma motivação aparente, provavelmente, se trata de uma expressão metafórica muito peculiar a esta atividade.

Picuá é de origem ${ }^{8}$ tupi, uma espécie de balaio ou cesto utilizado pelos índios. Já no garimpo, era uma "peça ger. de chifre em que os mineiros guardam diamantes" (HOUAISS; VILLAR, 2009) ou:

Picuá é de guardá o diamante $\{\ldots\}$ é um canudim assim, piquenim assim, curtim assim (gestos) tem gente que faiz uns grande, sabe, mais ele é mais ou meno assim (gestos), é... ês vem cuma tampinha, ro[lh]inha de... buriti ou ro[lh]inha de dessas coisa e picuá num pode se[r] vidro $\{\ldots\}$ não, picuá tem que se[r] osso ou madera, quê o vidro quebra né, diamante corta o vidro $\{\ldots\}$ aí é picuá de vidro num é apropriado pa guardá diamante, eu, eu é de, a gente faiz ele se põe dé, faiz de... é canela de lobo, o picuá, iss'é bom... é $\{\ldots\}$ picuá, canela de lobo, ôtos faiz cum cipó [...] né ôtos faiz cum taboca (G6E1).

Croar e croar de suruca são temos que indicam duas das maneiras de como o diamante sai no meio da forma, no caso, por cima dela, pois "s'ele croa é purque ele bate, ele vem pur cima da forma, aí cê bate, cê vê ele" (G6E1). Quando isto acontece, ainda no leito do rio, no momento em que o cascalho será passado pela suruca, diz-se que ele croou de suruca.

Nos dicionários, encontramos apenas o lexema croá que se remete a um tipo de planta $^{9}$, não apresentando nenhuma referência ao garimpo, nem mesmo um significado em que houvesse alguma aproximação de sentidos, como em cascalho desemburrado. Desta forma, podemos falar em uma semi-motivação somente em croar de suruca, devido ao acréscimo da locução adjetiva de suruca que, além disto, é outro caso em que temos estrutura substantivo + preposição + substantivo.

Quanto à unidade lexical croar poderia, de forma hipotética, ser o caso de uma síncope na estrutura do item lexial coroar, no entanto, como não é algo comprovável, consideremos que se trata de ressemantização, assim como acontece com bruaca, que, atualmente, é usada como xingamento.

Cortar a forma consiste no movimento de procurar pelo diamante remexendo o cascalho com uma pá: "agora o imbuxado cê tem que cortá a forma, pegá uma, uma pazinha e cortá a forma assim pa achá ele, se ele tivé imbuxado \{... é caçano ele, caçano assim (gestos), que ele imbuxado" (G9E1). A escolha por este verbo se explica pela maneira peculiar com que eles buscavam pela pedra que poderia estar por baixo da forma.

Usava-se a locução verbal estar queimando quando, no momento da lavação, os garimpeiros percebiam que não estava para bamburro, "Falava que tava quemano dimais (...) num pegava diamante, vasava $\{\ldots\}$ porque num tava pegano diamante, é cascái quemadô (risos) (...)" (G9E1). Não percebemos motivação aparente para esta expressão e, ao consultarmos o dicionário, não notamos também alguma analogia que pudesse ter sido feita, a não ser pelo fato de que se queimar é algo ruim e, talvez, o verbo queimar não

\footnotetext{
${ }^{8}$ Ver Nascentes (1966), p. 580.

9 “[...] planta terrestre ou saxícola (Neoglaziovia variegata), da fam. das bromeliáceas, nativa do Brasil (NE), de poucas folhas lineares e acuminadas, dispostas em roseta, inflorescência laxa com $25 \mathrm{~cm}$ de comprimento e com até 60 flores, de sépalas vermelhas e pétalas purpúreas; as folhas fornecem longas fibras, de grande resistência e durabilidade; carauá, caruá, coroá, coroatá, crauá, croá, gravatá [...]" (HOUAISS; VILLAR, 2009).
} 
fizesse menção exatamente ao cascalho, mas à situação dos garimpeiros que ficariam, à moda de uso gírio, queimados por não conseguirem pegar alguma pedra depois de tanto trabalho.

Bamburrar (verbo intransitivo) era utilizado no momento em que eles "tiravam a sorte grande", isto é, pegavam diamante "uns falava ' $\hat{E}$ esse ano eu bamburrei, peguei muito diamante', né... a expressão é essa né... 'Forguei ess'ano, tô forgado', essas é as expressão né” (G6E1). Quanto à especificidade deste termo, além das entrevistas, podemos comprová-la pela acepção dicionarizada, em que é classificada como regionalismo utilizado nos estados da Amazônia e Bahia: "encontrar por bambúrrio ('acaso') ouro, diamantes ou outras pedras preciosas, e enriquecer" (HOUAISS; VILLAR, 2009). Depois do trabalho de uma semana toda, este seria o momento decisivo e mais esperado por todos os garimpeiros, encontrar ali, ao virar a peneira, o motivo de sua busca: o diamante.

\section{Considerações finais}

A análise que realizamos neste estudo, através de uma abordagem terminológica, foi baseada nos princípios propostos pela Teoria Comunicativa da Terminologia (TCT). Nesta perspectiva, o termo é visto como uma unidade da língua ativada em uma determinada área de especialidade e que obedecerá ao mesmo comportamento morfossintático dos demais itens lexicais utilizados na língua em uso. Assim, poderemos encontrar nas mais variadas terminologias, casos de sinonímia, variação, ressemantização, neologia, polissemia dentre outros processos, que é o que tem sido constatado por meio das recentes pesquisas nesta área, como buscamos apresentar neste estudo.

Apesar de a Terminologia, no quadro das ciências do léxico, ser considerada a mais recente, sabemos que a preocupação com os vocabulários terminológicos é antiga. No caso do garimpo, encontramos algumas pesquisas no campo da Geografia, da História e da Filologia que chegaram a disponibilizar um vocabulário ao final do trabalho, mas nada aprofundado e que apresentasse uma preocupação de cunho linguístico, algo totalmente compreensível, por não ser o foco destes estudos naquele momento, mas que nos foram de grande valia para conhecermos mais sobre a história desta atividade.

Encontramos, também, dicionários de Gemologia e Mineralogia, que são áreas científicas consagradas socialmente, no entanto, nada especificamente voltado para o garimpo, provavelmente, por ser uma atividade que, desde o seu surgimento, foi colocada à margem e praticada por pessoas que, em sua maioria, não pertenciam às famílias abastadas.

Entretanto, parte do vocabulário terminológico concernente à técnica artesanal de extração de diamantes se encontra preservado na memória daqueles que a praticaram, nos tempos pretéritos, na região, hoje, conhecida como Três Ranchos. Muitos destes homens, ainda vivos, com seus quase setenta, oitenta anos de idade, nos concederam entrevistas em que, saudosos, contaram sobre a lida no garimpo, deixando croar em sua fala os termos dentre os quais apresentamos alguns neste estudo.

\section{Referências}

BARROS, L. A. Curso Básico de Terminologia. São Paulo: EDUSP, 2004, p. 25-96.

COSTA, Luciano Rodrigues. Os garimpos clandestinos de ouro em Minas Gerias e no Brasil: tradição e mudança. História e Perspectivas, Uberlândia, n. 37-37, p. 247-279, jan/dez. 2007. 
GONÇALVES, Ricardo Junior de Assis. A vida pode mudar com a virada da peneira: (re)organização do território e do trabalho nos garimpos de diamantes em Coromandel/MG. 2012. 272 f. Dissertação (Mestrado em Geografia) - Universidade Federal de Goiás - Campus Catalão. Catalão, 2012.

HOUAISS, Antônio; VILLAR, Mauro de Salles. Dicionário Eletrônico Houaiss da língua portuguesa, Instituto Antônio Houaiss de Lexicografia e Banco de Dados da Língua Portuguesa S/C Ltda., Rio de Janeiro: Editora Objetiva, 2009.

KRIEGER, Maria da Graça. A heterogeneidade do léxico especializado e perfis terminológicos. In: MURAKAWA, Clotilde de A. A.; NADIN, Odair Luiz. Terminologia: uma ciência interdisciplinar. São Paulo: Cultura Acadêmica, 2014. p. 23-42.

FINATTO, M. José B. Introdução à Terminologia: teoria e prática. São Paulo: Contexto, 2004. p. 75-120.

MACHADO FILHO, Aires da Mata. O negro e o garimpo em Minas Gerais. Rio de Janeiro: Civilização Brasileira S. A., 1964.

MURAKAWA, Clotilde de A. A. Vocabulário das enfermidades em documento do Brasil colonial: o relato de "Prodigiosa Lagoa" (1749). In: MURAKAWA, Clotilde de A. A.; NADIN, Odair Luiz. Terminologia: uma ciência interdisciplinar. São Paulo: Cultura Acadêmica, 2014. p. 83-101.

NASCENTES, Antenor. Dicionário Etimológico Resumido. Rio de Janeiro: Oficinas do Serviço Gráfico do IBGE, 1966.

SILVA, Sonilda Aparecida de Fátima. Campos Verdes: memória, história e saberes. 2006. 125 f. Dissertação (Mestrado Profissional em Gestão do Patrimônio Cultural) Universidade Católica de Goiás. Goiânia, 2006.

SOUSA, José Luiz Vaz de. Pobres garimpeiros de riqueza: a geografia dos diamantes em Três Ranchos-Goiás. 2012. 170 f. Dissertação (Mestrado em Geografia) - Universidade Federal de Goiás - Campus Catalão. Catalão, 2012. 